\title{
Patient Burden and Real-World Management of Chemotherapy-Induced Myelosuppression: Results from an Online Survey of Patients with Solid Tumors
}

\author{
Robert S. Epstein · Matti S. Aapro • Upal K. Basu Roy • \\ Tehseen Salimi · JoAnn Krenitsky • Megan L. Leone-Perkins • \\ Cynthia Girman · Courtney Schlusser · Jeffrey Crawford
}

Received: May 29, 2020 / Published online: July 8, 2020

(C) The Author(s) 2020

\begin{abstract}
Introduction: Chemotherapy-induced myelosuppression (CIM) is one of the most common dose-limiting complications of cancer treatment, and is associated with a range of debilitating symptoms that can significantly impact patients' quality of life. The purpose of this study was to understand patients' perspectives
\end{abstract}

Digital Features To view digital features for this article go to https://doi.org/10.6084/m9.figshare.12488759.

R. S. Epstein $(\bowtie) \cdot J$. Krenitsky

Epstein Health, LLC, Woodcliff Lake, NJ, USA

e-mail: repstein@epsteinhealth.com

M. S. Aapro

Clinique de Genolier, Genolier, Switzerland

U. K. Basu Roy

LUNGevity Foundation, Bethesda, MD, USA

T. Salimi

G1 Therapeutics, Inc., Research Triangle Park, NC,

USA

M. L. Leone-Perkins

HealthiVibe, Corrona, LLC, Arlington, VA, USA

C. Girman

CERobs Consulting, LLC, Chapel Hill, NC, USA

C. Girman · C. Schlusser

UNC Gillings School of Global Public Health,

Chapel Hill, NC, USA

J. Crawford

Duke University Medical Center, Durham, NC, USA on how the side effects of CIM are managed in routine clinical practice.

Methods: An online survey was conducted of participants with breast, lung, or colorectal cancer who had received chemotherapy treatment within the past 12 months, and had experienced at least one episode of myelosuppression in the past year. The survey was administered with predominantly close-ended questions, and lay definitions of key terms were provided to aid response selection.

Results: Of 301 participants who completed the online survey, 153 (51\%) had breast cancer, $100(33 \%)$ had lung cancer, and 48 (16\%) had colorectal cancer. Anemia, neutropenia, lymphopenia, and thrombocytopenia were reported by $61 \%, 59 \%, 37 \%$, and $34 \%$ of participants, respectively. Most participants (79\%) reported having received treatment for CIM, and $64 \%$ of participants recalled chemotherapy dose modifications as a result of CIM. Although most participants believed their oncologist was aware of the side effects of CIM, and treated them quickly, $30 \%$ of participants felt their oncologists did not understand how uncomfortable they were due to the side effects of CIM. Overall, $88 \%$ of participants considered CIM to have a moderate or major impact on their lives. Conclusion: The data highlight that despite the various methods used to address CIM, and the patient-focused approach of oncologists, the real-world impact of CIM on patients is substantial. Improving communication between 
patients and health care providers may help improve patients' understanding of CIM, and foster shared decision-making in terms of treatment. Additional insights from patients should be obtained to further elucidate the totality of life burden associated with CIM.

\section{PLAIN LANGUAGE SUMMARY}

This study looked at people with cancer who received chemotherapy and developed a condition where their bone marrow activity was reduced, called myelosuppression. This meant they had fewer red blood cells that carry oxygen around the body, white blood cells that help fight infections, and platelets that help the blood to clot. The researchers wanted to understand how chemotherapy-induced myelosuppression affects peoples' lives and their cancer treatment, and people's experiences of treatment for myelosuppression. Overall, 301 people in the USA with breast, lung, or large bowel (colorectal) cancer completed an online survey. They had all received chemotherapy in the last year, and had myelosuppression at least once during their treatment. The survey showed that around 8 in 10 people $(79 \%)$ had to be treated for myelosuppression, and around 7 in 10 people (73\%) felt they received treatment for myelosuppression quickly. Chemotherapy was delayed, reduced, or stopped because of myelosuppression in around 6 in 10 people (64\%). Around 3 in 10 people $(30 \%)$ felt their oncologist did not understand the discomfort that myelosuppression caused them, and around 9 in 10 people $(88 \%)$ felt that myelosuppression made their quality of life worse. The researchers concluded that because myelosuppression impacts peoples' lives and their ability to keep receiving chemotherapy to treat their cancer, effective prevention and treatment for this condition are important. Better communication between people and their health care teams could help them to understand how people experience myelosuppression and make plans for treatment together.
Keywords: Anemia; Chemotherapy; Myelosuppression; Neutropenia; Oncology; Online survey; Patient burden; Real-world; Symptom management; Thrombocytopenia

\section{Key Summary Points}

Why carry out this study?

The side effects of chemotherapy, including myelosuppression, remain a major source of concern for both patients and health care providers.

The consequences of chemotherapyinduced myelosuppression (CIM) include anemia, thrombocytopenia, and neutropenia, all of which can cause severe complications, and limit the ability of patients to receive chemotherapy on time and at standard-of-care doses.

Prior research has documented patients' perceptions of the side effects of chemotherapy; however, research into the real-world impact of CIM on patients' lives is limited, and the 'patient voice' on CIM, and how it is currently managed, is lacking.

\section{What was learned from the study?}

Despite the current availability and use of various supportive care interventions, CIM places a substantial burden on patients with advanced solid tumors, impacting many aspects of their daily lives.

This survey provides valuable insights into patients' perspectives on the impact and management of CIM, and suggests that methods to prevent or proactively manage CIM could improve the quality of life of patients receiving chemotherapy. 


\section{INTRODUCTION}

Myelosuppression is an important treatmentrelated toxicity among patients with cancer [1-3], and occurs when the actively dividing hematopoietic stem and progenitor cells (HSPCs) in the bone marrow, which give rise to blood cell lineages, are damaged by cytotoxic chemotherapy. Chemotherapy-induced myelosuppression (CIM) commonly manifests as anemia, neutropenia, thrombocytopenia, and/ or lymphopenia [1,4-6], and often results in an increased risk of life-threatening infections, shortness of breath, fatigue, and, potentially, excess bleeding. CIM is currently managed with chemotherapy dose reductions and delays, in addition to rescue interventions that stimulate or mobilize white cells (growth factors, such as granulocyte colony-stimulating factors [GCSFs]); replenish red blood cells (RBCs) and platelets (transfusions); or stimulate RBC precursors (growth factors, such as erythropoiesisstimulating agents [ESAs]) [4, 7-9]. Despite the use of these interventions, however, clinically significant CIM continues to be a major acute toxicity of cytotoxic chemotherapy, possibly because currently available interventions are administered reactively, i.e., after HSPCs have been damaged by chemotherapy. The wide application of chemotherapy dose reductions and/or delays can also reduce the dose intensity of the chemotherapy and, potentially, its intended antitumor efficacy [3, 9-11].

CIM is particularly relevant for patients with small cell lung cancer (SCLC), breast cancer, and colorectal cancer (CRC), for which chemotherapy, alone, or in combination with immune checkpoint inhibitors, remains a cornerstone of treatment [12-16]. A systematic literature review to assess the real-world effectiveness and tolerability of treatments for SCLC, for example, showed that hematologic toxicities were the most commonly reported adverse events (AEs); neutropenia was reported in approximately two-thirds of patients receiving first-line chemotherapy, and almost threequarters of patients receiving second-line chemotherapy [17].
Research into patients' perceptions of the side effects of chemotherapy, including those associated with CIM, has been well documented, particularly with regard to symptoms of fatigue and effects on family [18-22]. Overall, these studies suggest that patients' concerns extend beyond physical symptoms to include non-physical concerns over daily routines, emotional well-being, and relationships $[19,21-23]$. By comparison, much less is known about how the management of CIM-associated side effects impacts patients. One survey of 15,785 adult cancer patients assessed the burden of time associated with medical visits for the management of chemotherapy-induced anemia (CIA) and neutropenia on patients and caregivers, and found that each visit involved approximately $2 \mathrm{~h}$ for the patient and over $1 \mathrm{~h}$ for caregivers [24]. Likewise, several surveys conducted to determine the impact of blood transfusions on patients with CIA have concluded that the time spent travelling to medical facilities, along with blood testing and the procedure itself, presents a considerable burden to patients [24-26]. While these studies highlight the logistic burden associated with CIM, there remains a need for more research into the broader impact that CIM and its management has on patients' lives, and to raise awareness among patients regarding the contribution of CIM to the overall toxicities associated with chemotherapy.

The purpose of the current study was to capture the perceptions, experiences, and challenges that patients encounter when diagnosed with myelosuppression as part of chemotherapy treatment for advanced solid tumors. Here, we describe patients' perspectives on the management of CIM among those with breast, lung, and colorectal cancers, and the overall impact that myelosuppression has on patients' lives.

\section{METHODS}

\section{Study Objectives and Format}

The objectives of the study were to understand what treatments were administered for CIM and the challenges that patients encountered in 
receiving these; determine from a patient perspective whether CIM impacted dose/frequency of chemotherapy; gain insights into which member of the care team paid most attention to symptoms associated with CIM; and to capture the "patient voice" in how CIM impacted their life.

The study was conducted in accordance with the Declaration of Helsinki, and electronic consent was obtained from all participants prior to study entry. The study was reviewed by the Sterling institutional review board (IRB), and granted exemption status according to Department of Health and Human Services research criteria, signifying that full IRB review was not required.

\section{Survey Population}

Participants were identified from an online US panel of patients with a wide range of health conditions, including cancer. The target sample size was 300 participants living with breast cancer, lung cancer, or CRC, with a target ratio of 120:90:90 per cancer type, respectively. Male and female participants aged 18 years or more were included if they had received chemotherapy treatment within the past 12 months, and had experienced at least one episode of myelosuppression in the past year, encompassing the following: required blood transfusion; required G-CSF or granulocyte macrophage colonystimulating factor (GM-CSF); required platelet transfusion; had a serious infection such as pneumonia or sepsis after receiving chemotherapy treatment; required ESAs to increase RBC count; or diagnosed with myelosuppression but with no treatment intervention.

\section{Research Instrument Development}

The survey was designed, as per the study objectives, considering a review of published literature, and the draft questions were reviewed by experts for scientific content and question design. Questions, including screening and demographic questions, as well as core survey content, were presented sequentially in several formats, which included a choice of one response from a defined list of possible statements; questions that asked the participant to choose multiple responses (e.g., Select all that apply); dichotomous questions (Yes/No); and statements where the participant was asked to indicate their agreement using a Likert scale (e.g., $\quad 1=$ Strongly disagree, $2=$ Disagree, $3=$ Neutral $/$ not sure, $4=$ Agree, $5=$ Strongly agree). Lay definitions of key terms were provided (upon cursor selection) to aid response selection (Table 1). Participants were also asked to provide verbatim responses to a single openended question about how the side effects from myelosuppression impacted their lives.

Table 1 Lay definitions of key terms

\begin{tabular}{ll}
\hline Term & Explanation \\
\hline Anemia & Fewer/less red blood cells, which sometimes causes you to be tired \\
Lymphocytes & Types of white blood cells that work to fight illness and disease \\
Lymphopenia & Fewer/less lymphocytes, which sometimes increases your risk of infection \\
Myelosuppression & A decrease in bone marrow activity that results in the reduced production of blood cells. \\
& Myelosuppression is a common side effect of chemotherapy \\
Neutropenia & Fewer/less white blood cells, which sometimes increases your risk of infection \\
Platelets & Tiny blood cells that help your body form clots to stop bleeding \\
Thrombocytopenia & Fewer/less platelets, which sometimes increases your risk of bleeding
\end{tabular}




\section{Data Analysis}

Data were aggregated to ensure anonymity and key findings summarized using descriptive statistics. Chi-square tests were used to calculate $p$ values (MS Excel).

\section{RESULTS}

A total of 2908 participants started the survey, of whom 2496 were disqualified, most commonly for not having received chemotherapy in the previous 12 months $(n=1269)$ or for not having lung, breast, or colorectal cancer $(n=334)$. A further 111 participants only partially completed the survey and were excluded from the analysis. The full survey was completed by 301 participants between November 11, 2019 and December 8, 2019. Of these, 291 (97\%) recalled being told by their health care provider (HCP) that they had at least one episode of myelosuppression, and 10 (3\%) recalled receiving treatment associated with myelosuppression.

Sixty percent of the participants were female, most (80\%) were under 60 years of age, and $60 \%$ were working (Table 2). Fifty-one percent of the participants had breast cancer, 33\% had lung cancer (of whom $46 \%$ had SCLC), and $16 \%$ had CRC. Seventy-five percent of participants had been diagnosed with cancer within the previous 3 years. All participants self-identified as having experienced some form of myelosuppression (anemia, neutropenia, thrombocytopenia, lymphopenia) in the past year. Self-reported

Table 2 Participant baseline demographics, clinical characteristics, and myelosuppression

\begin{tabular}{|c|c|c|c|c|}
\hline & Breast cancer & Lung cancer & Colorectal cancer & Total \\
\hline Patients, $n$ & 153 & 100 & 48 & 301 \\
\hline \multicolumn{5}{|l|}{ Gender, $n(\%)$} \\
\hline Male & $21(14)$ & $67(67)$ & $32(67)$ & $120(40)$ \\
\hline Female & $132(86)$ & $33(33)$ & $15(31)$ & $180(60)$ \\
\hline Other & 0 & 0 & $1(2)$ & $1(<1)$ \\
\hline \multicolumn{5}{|l|}{ Age group, years, $n$ (\%) } \\
\hline $18-59$ & $134(88)$ & $75(75)$ & $32(67)$ & $241(80)$ \\
\hline$\geq 60$ & $19(12)$ & $25(25)$ & $16(33)$ & $60(20)$ \\
\hline Currently working (full or part time), $n$ (\%) & $92(60)$ & $65(65)$ & $24(50)$ & $181(60)$ \\
\hline \multicolumn{5}{|l|}{ Years since cancer diagnosis, $n(\%)$} \\
\hline$<1$ & $37(24)$ & $19(19)$ & $11(23)$ & $67(22)$ \\
\hline $1-3$ & $75(49)$ & $53(53)$ & $29(60)$ & $157(52)$ \\
\hline$\geq 4$ & $40(26)$ & $28(28)$ & $8(17)$ & $76(25)$ \\
\hline Not answered & $1(1)$ & $0(0)$ & $0(0)$ & $1(<1)$ \\
\hline \multicolumn{5}{|l|}{ Myelosuppression, $n(\%)^{\mathrm{a}}$} \\
\hline Anemia & $103(67)$ & $51(51)$ & $30(63)$ & $184(61)$ \\
\hline Neutropenia & $80(52)$ & $61(61)$ & $37(77)$ & $178(59)$ \\
\hline Lymphopenia & $56(37)$ & $32(32)$ & $24(50)$ & $112(37)$ \\
\hline Thrombocytopenia & $47(31)$ & $36(36)$ & $18(38)$ & $101(34)$ \\
\hline
\end{tabular}

${ }^{\text {a }}$ Participants could select more than one option 


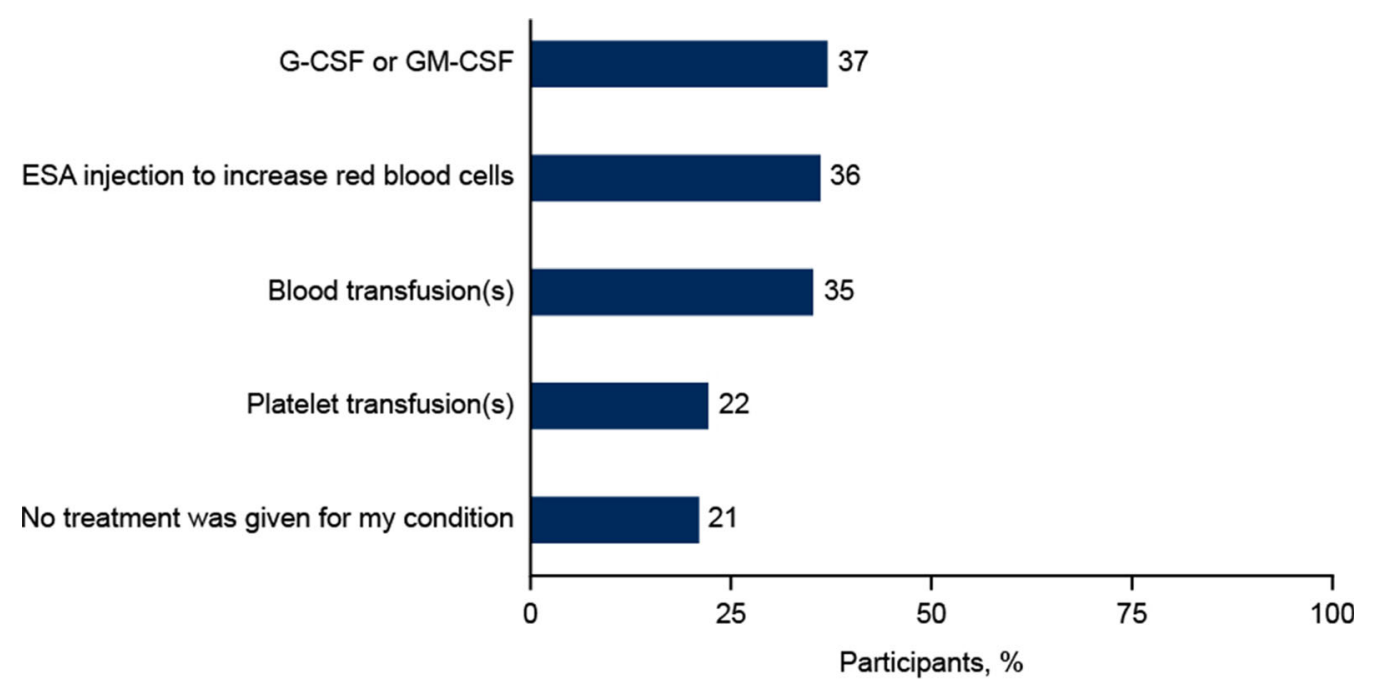

Fig. 1 Interventions received for myelosuppression. Participants could select more than one response. ESA erythropoiesis-stimulating agents, $G-C S F$ granulocyte

comorbidities included diabetes (30\%), depression $(28 \%)$, and hypertension (23\%).

Most participants reported that they had been diagnosed with anemia (61\%) or neutropenia (59\%), while fewer participants reported a doctor's diagnosis of lymphopenia (37\%) or thrombocytopenia (34\%; Table 2). Approximately one-third of participants reported receiving either $\mathrm{G}(\mathrm{M})$-CSF, ESAs, or RBC transfusions $(37 \%, 36 \%$, and $35 \%$, respectively); platelet transfusions were reported by $22 \%$ of participants; and $21 \%$ reported no treatment (Fig. 1). Illustrative comments in response to the open-ended question included:

I handled the side effects of myelosuppression pretty well during the chemotherapy. The thing that bothered me the most was the [pegfilgrastim] and I hated being injected. I had terrible bone pain after each shot.

[Myelosuppression] affected me greatly. I felt the side effects daily. My immune system was affected, and I had to get shots to increase my [blood] counts.

In total, $64 \%$ of participants recalled chemotherapy dose delays, reductions, discontinuations, and/or changes due to myelosuppression (Fig. 2). colony-stimulating factor, GM-CSF granulocyte macrophage colony-stimulating factor

Myelosuppression was most frequently managed by an oncologist, and most participants thought that their oncologist was aware of their side effects and treated them quickly (Table 3); however, $29 \%$ of participants felt that their side effects were not treated, and 30\% felt that their oncologist did not understand how uncomfortable they were as a result of myelosuppression side effects. Results were similar across the three tumor types (Table 3 ).

Most participants (88\%) considered myelosuppression to have a moderate or major overall impact on life (Table 4). Participant-reported impact of myelosuppression was significantly higher among participants aged below 50 years compared with those aged at least 50 years $(p=0.01)$; however, no significant differences were observed when participants were stratified by gender, employment status, cancer type, or comorbidities (depression, diabetes, hypertension).

Some illustrative verbatim responses regarding the impact of myelosuppression side effects included the following:

Did not get out as much, not able to work, always feeling tired. Had to take preventative measures to guard against diseases and germs. 


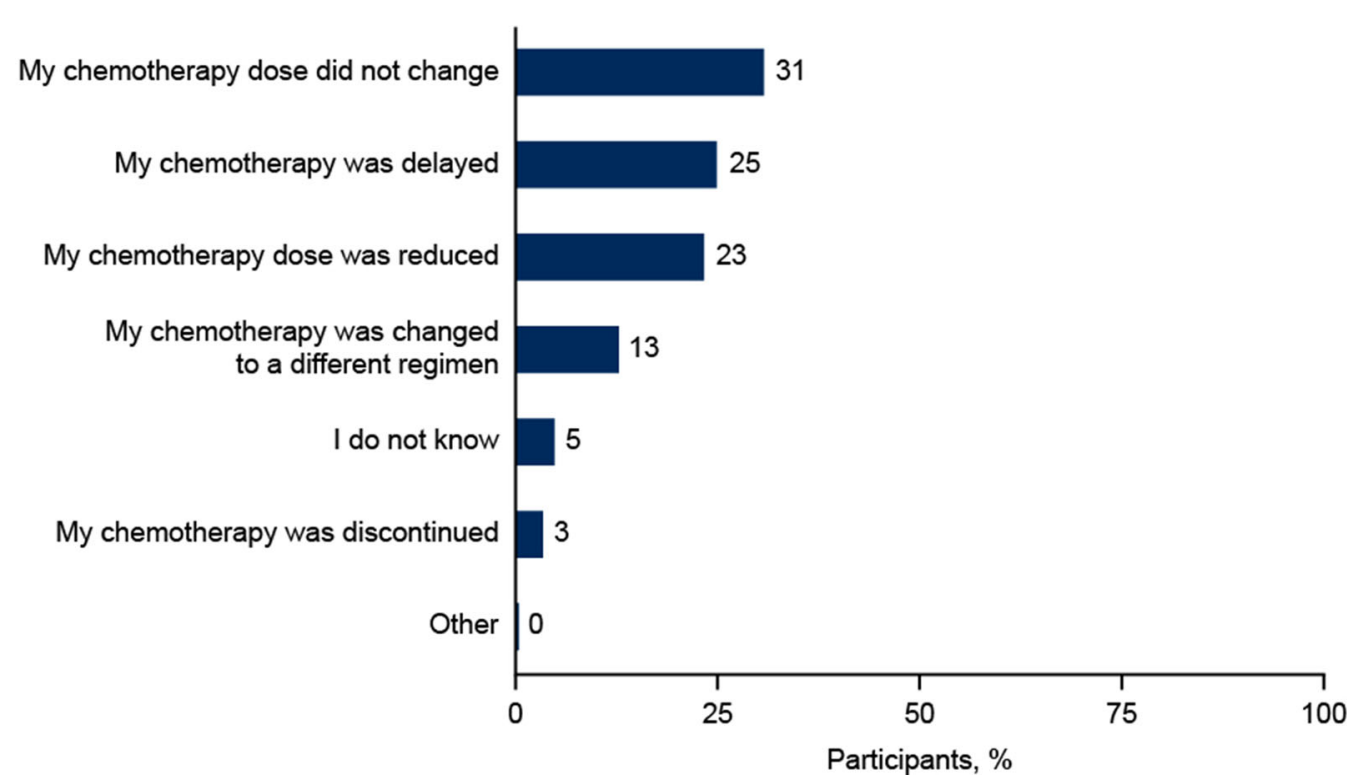

Fig. 2 Impact of myelosuppression on chemotherapy treatment

Table 3 Side effect management by oncologists, as reported by participants

\begin{tabular}{|c|c|c|c|c|}
\hline Statement $^{\mathrm{a}}$ & $\begin{array}{l}\text { Breast } \\
(n=153)\end{array}$ & $\begin{array}{l}\text { Lung } \\
(n=100)\end{array}$ & $\begin{array}{l}\text { CRC } \\
(n=48)\end{array}$ & $\begin{array}{l}\text { Total } \\
(N=301)\end{array}$ \\
\hline Oncologist warned me to expect side effects from chemotherapy, \% & 75 & 76 & 77 & 76 \\
\hline Oncologist did not treat my side effects from myelosuppression, \% & 29 & 29 & 29 & 29 \\
\hline Oncologist treated my side effects quickly, \% & 73 & 74 & 69 & 73 \\
\hline $\begin{array}{l}\text { Oncologist did not understand how uncomfortable I was from the } \\
\text { side effects I experienced, \% }\end{array}$ & 33 & 28 & 25 & 30 \\
\hline
\end{tabular}

${ }^{\text {a }}$ Participants selected 4 (Agree) or 5 (Strongly agree) on a 1-5 scale

It has made everyday life more difficult in all areas.

I had to severely curtail my social activities so I was not exposed to germs. I avoided family holiday activities [and] had some depression because of lack of social interaction and concern over potential infection.

\section{DISCUSSION}

Studies seeking to gain insight into patients' perspectives on the burden of CIM are important, as hematologic side effects can have a substantial negative impact on patients' quality of life and may contribute to suboptimal treatment outcomes $[1,4,6,19]$. Many studies have sought to understand patients' perceptions of the symptoms associated with CIM, but few studies have been designed to better understand patients' perspectives on the overall impact of CIM and how it is managed in daily practice.

In the current survey, anemia and neutropenia were reported most commonly (61\% and $59 \%$ of participants, respectively), whereas thrombocytopenia and lymphopenia were relatively less common (34-37\% of participants). The actual rates of myelosuppression reported in the survey are higher than would be expected in an all-comer population, given that we focused only on participants with a diagnosis of 
Table 4 Relationship of demographics and clinical characteristics to perceived overall impact of myelosuppressi

\begin{tabular}{|c|c|c|c|c|c|}
\hline & Patients, $n$ & Minor impact, $n$ (\%) & Moderate impact, $n(\%)$ & Major impact, $n(\%)$ & $p$ value \\
\hline All patients & 301 & $36(12)$ & $146(48.5)$ & $119(39.5)$ & - \\
\hline \multicolumn{6}{|l|}{ Age } \\
\hline$<50$ years & 191 & $15(8)$ & $98(51)$ & $78(41)$ & \multirow[t]{2}{*}{0.01} \\
\hline$\geq 50$ years & 110 & $21(19)$ & $48(44)$ & $41(37)$ & \\
\hline \multicolumn{6}{|l|}{ Gender } \\
\hline Male & 120 & $19(16)$ & $61(51)$ & $40(33)$ & \multirow[t]{2}{*}{0.26} \\
\hline Female & 180 & $17(9)$ & $84(47)$ & $79(44)$ & \\
\hline \multicolumn{6}{|l|}{ Working status } \\
\hline Working & 181 & $19(11)$ & $93(51)$ & $69(38)$ & \multirow[t]{2}{*}{0.40} \\
\hline Not working & 120 & $17(14)$ & $53(44)$ & $50(42)$ & \\
\hline \multicolumn{6}{|l|}{ Cancer type } \\
\hline Breast & 153 & $15(10)$ & $75(49)$ & $63(41)$ & \multirow[t]{3}{*}{0.59} \\
\hline Lung & 100 & $13(13)$ & $46(46)$ & $41(41)$ & \\
\hline Colorectal & 48 & $8(17)$ & $25(52)$ & $15(31)$ & \\
\hline \multicolumn{6}{|l|}{ Comorbidities } \\
\hline \multicolumn{6}{|l|}{ Depression } \\
\hline Yes & 85 & $6(7)$ & $46(54)$ & $33(39)$ & \multirow[t]{2}{*}{0.20} \\
\hline No & 216 & $30(14)$ & $100(46)$ & $86(40)$ & \\
\hline \multicolumn{6}{|l|}{ Diabetes } \\
\hline Yes & 91 & $8(9)$ & $46(51)$ & $37(41)$ & \multirow[t]{2}{*}{0.54} \\
\hline No & 210 & $28(13)$ & $100(48)$ & $82(39)$ & \\
\hline \multicolumn{6}{|l|}{ Hypertension } \\
\hline Yes & 69 & $9(13)$ & $33(48)$ & $27(39)$ & \multirow[t]{2}{*}{0.95} \\
\hline No & 232 & $27(12)$ & $113(49)$ & $92(40)$ & \\
\hline
\end{tabular}

myelosuppression and/or treatment for myelosuppression. In a study of electronic medical records from 339 evaluable patients diagnosed with SCLC, for example, real-world rates of chemotherapy-induced neutropenia, anemia, and thrombocytopenia were $45 \%, 41 \%$, and $25 \%$, respectively [27]. The finding that anemia and neutropenia were more common than thrombocytopenia is consistent with the prescribing information for a range of myelosuppressive chemotherapy treatments, although many report neutropenia as being more common than anemia [3]. It is possible that the relatively broad inclusion criteria in this online survey may have led to overestimation of the incidence of CIA, since participants with anemia resulting from the cancer itself or other underlying causes would also have been included.

In line with the finding that most participants were diagnosed with anemia or neutropenia, G(M)-CSF, ESAs, and RBC transfusions 
were described as the most common supportive care interventions, each being reported in approximately one-third of participants. Retrospective studies of supportive care use among US patients with solid tumors or lymphoma have shown that $35-55 \%$ of patients receive prophylaxis with myeloid growth factors $[28,29]$; however, far fewer patients receive ESAs $[27,30]$. The low utilization of ESAs in the USA may partly reflect the US Food and Drug Administration's decision in 2007 to restrict ESA use to patients with a hemoglobin $(\mathrm{Hb})$ level of less than $10 \mathrm{~g} / \mathrm{dL}$ owing to concerns over rapid tumor progression and shortened overall survival with ESAs at $\mathrm{Hb}$ greater than $12 \mathrm{~g} / \mathrm{dL}$ [31]. Similarly, there has been a shift toward a more restrictive policy on transfusions for CIA in recent years, with guidelines supporting a $\mathrm{Hb}$ threshold of less than $7 \mathrm{~g} / \mathrm{dL}$ for most patients [32]. Despite these recommendations, the findings of the current study, along with previous reports on patterns of supportive care use in patients on chemotherapy, suggest that, in general, interventions such as growth factors and transfusions are commonly used. Indeed, only $21 \%$ of survey participants in the current study reported receiving no treatment. This finding is notable, as the supportive care interventions themselves can present additional risks, such as bone pain with G(M)-CSF; thrombotic events with ESAs; and transfusion reactions and infections with $\mathrm{RBC}$ and platelet transfusions; as well as being a burden to patients [7, 8, 24-26, 33].

Approximately two-thirds of survey participants experienced an issue with continuing on their current chemotherapy regimen due to myelosuppression, reflecting the substantial impact of hematologic side effects on standardof-care treatment schedules and doses. This is in line with findings from studies in patients with advanced non-small cell lung cancer and breast cancer. In these studies, chemotherapy was delayed by at least 1 week in approximately one-third of patients, and approximately 40\% of patients had a relative dose intensity of less than $85 \%[9,34]$. Such dose modifications are clinically relevant, as maintaining appropriate dose intensity is important in both the curative setting and in treatment with palliative intent
[3]. For this reason, the development of equally effective chemotherapy regimens that carry less long-term risks has been an important focus of research. The frequent, uninterrupted administration of low-dose (metronomic) chemotherapy, for example, is thought to result in sustained, low blood levels of chemotherapy, with fewer side effects, and a reduced need for supportive therapies [35]. However, although alternative dosing strategies may be useful to reduce CIM, they should be limited to situations where dose reductions are not expected to compromise long-term outcomes.

Participants reported that myelosuppression was most frequently managed by an oncologist, as opposed to a nurse, physician assistant, or other HCP. This differs to other areas of supportive care, such as the management of nausea and vomiting, where oncology nurses are often better placed to manage side effects, as they have more frequent contact with individual patients and offer a holistic approach to care $[36,37]$. Nevertheless, most participants had confidence in their oncologist to be aware of and treat side effects, although some perceived that their oncologists did not understand the impact that side effects had on their lives. A previous study examining patients' perceptions of the physician-patient relationship and communication about AEs also found that most patients reported having a good relationship with their physician, and that they had extensive discussions about what side effects might occur. However, those discussions did not always provide patients with sufficient understanding or adequately equip patients to cope with the AEs [38]. Overall, the results are encouraging, but suggest that there is a need for improved communication between patients and their treating physician, both in terms of improving patients' understanding of potential side effects and in listening to their perspectives on how these events affect everyday life. Indeed, improved patient-physician communication would help foster shared decision-making, especially when critical decisions regarding treatment discontinuation or treatment changes must be made.

It is notable that most participants, particularly younger participants, felt that 
myelosuppression side effects had a moderateto-major life impact, despite the fact that most perceived their symptoms to be expected and treated quickly. In particular, in their verbatim responses, many participants described a substantial negative impact on their ability to carry out daily tasks, due to fatigue and concerns about infection. This is especially pertinent in light of the COVID-19 pandemic that occurred following the completion of this survey, which is likely to further exacerbate the impact of myelosuppression on patients' lives by creating an additional burden to health care systems and by heightening fears that a weakened immune system will put oncology patients at risk of severe complications from the virus $[39,40]$.

One limitation of this study is that the use of an online patient database to engage participants may have created bias in favor of reflecting the preferences of participants with more familiarity with online technologies, or who were healthier than the average oncology patient. In principle, patients with worse disease characteristics, requiring aggressive treatment for cancer and/or CIM may not have been interested or able to participate in the survey. The study is also based solely on patient selfreport, and the extent to which patients can accurately recall this type of information is not known. Thus, these findings should be considered alongside findings from other patient populations and using other methods, such as prospective observation, patient diaries, and/or interviews within clinical settings, to confirm and extend the findings. On the other hand, a key strength of using an online platform is that participants may be more willing to share information than in a face-to-face interview, and may be less likely to be directed toward a socially desirable response. Additionally, the use of verbatim responses provides important information on aspects of the patient burden of CIM that would not otherwise be captured in a closed response questionnaire.

\section{CONCLUSION}

Despite the use of chemotherapy dose reductions and delays, $\mathrm{G}(\mathrm{M})$-CSF, ESA injections, and blood transfusions to address CIM, the findings of this survey suggest that the real-world impact of myelosuppression on patients is substantial, with almost all participants reporting a moderate or major impact on their lives. The data highlight that there is an unmet need to prevent or proactively manage CIM to improve patients' quality of life and to improve communication between HCPs and their patients.

\section{ACKNOWLEDGEMENTS}

We give special thanks to the patients who participated in the survey, and to Dr Upal K Basu Roy from the LUNGevity Foundation (lung cancer advocacy community) for his involvement and authorship.

Funding. Sponsorship for this study, the Rapid Service and Open Access Fees were funded by G1 Therapeutics, Inc. (Research Triangle Park, NC, USA).

Medical Writing and Editorial Assistance. Medical writing assistance in the preparation of this article was provided by Fiona Scott, contracted by Alligent Europe (Envision Pharma Group). Plain language writing support was provided by Lauri Arnstein, Envision Pharma Group. Support for all assistance was funded by G1 Therapeutics, Inc.

Authorship. All named authors meet the International Committee of Medical Journal Editors (ICMJE) criteria for authorship for this article, take responsibility for the integrity of the work as a whole, and have given their approval for this version to be published.

Prior Presentation. Data from this study have been previously published, in part, as a poster presentation at the International Society for Pharmacoeconomics and Outcomes Research (ISPOR) 2020 virtual conference, May 18-20, and as an electronic abstract at the American Society of Clinical Oncology (ASCO) 2020 annual meeting (virtual format), May 29-31. 
Disclosures. Robert S. Epstein is a consultant for G1 Therapeutics, Inc. and serves on the board for Proteus Digital, Fate Therapeutics, Illumina, Veracyte, and Decipher Biosciences. Matti S. Aapro has served as a consultant for Amgen, Bristol Myers Squibb, Daiichi Sankyo, Fresenius Kabi, G1 Therapeutics, Inc., Genomic Health, Helsinn Healthcare, Merck KGaK, Merck, Novartis, Pfizer, Pierre Fabre, Roche, Sandoz, Tesaro, and Vifor Pharma; is on the Speakers' Bureau for Accord Research, Amgen, Biocon, Dr Reed, Genomic Health, Helsinn Healthcare, Mundipharma, Novartis, Pierre Fabre, Pfizer, Roche, Sandoz, Taiho Pharmaceutical, Tesaro, and Vifor Pharma; and has received research funding from Helsinn Healthcare, Novartis, Pierre Fabre, and Sandoz. Upal K. Basu Roy has received research funding from Astra Zeneca, Bristol Myers Squibb Foundation, and Merck unrelated to this project. Tehseen Salimi was a paid employee of G1 Therapeutics, Inc., at the time of study completion and manuscript preparation, and is currently a paid employee of Taiho Oncology, Inc. JoAnn Krenitsky is a consultant for G1 Therapeutics, Inc. Megan L. Leone-Perkins is a paid consultant for HealthiVibe, a division of Corrona LLC. Cynthia Girman is a consultant for G1 Therapeutics, Inc., and Epstein Health, LLC. Courtney Schlusser is a consultant for G1 Therapeutics, Inc., and Epstein Health, LLC. Jeffrey Crawford has served as an advisor to Amgen, Coherus, G1 Therapeutics, Inc., and Pfizer.

Compliance with Ethics Guidelines. The study was conducted in accordance with the Declaration of Helsinki, and electronic consent was obtained from all participants prior to study entry. The study was reviewed by the Sterling IRB, and granted exemption status according to Department of Health and Human Services research criteria, signifying that full IRB review was not required.

Data Availability. The datasets generated during and/or analyzed during the current study are available from the corresponding author on reasonable request.
Open Access. This article is licensed under a Creative Commons Attribution-NonCommercial 4.0 International License, which permits any non-commercial use, sharing, adaptation, distribution and reproduction in any medium or format, as long as you give appropriate credit to the original author(s) and the source, provide a link to the Creative Commons licence, and indicate if changes were made. The images or other third party material in this article are included in the article's Creative Commons licence, unless indicated otherwise in a credit line to the material. If material is not included in the article's Creative Commons licence and your intended use is not permitted by statutory regulation or exceeds the permitted use, you will need to obtain permission directly from the copyright holder. To view a copy of this licence, visit http://creativecommons.org/licenses/by$\mathrm{nc} / 4.0 /$.

\section{REFERENCES}

1. Barreto JN, McCullough KB, Ice LL, Smith JA. Antineoplastic agents and the associated myelosuppressive effects: a review. J Pharm Pract. 2014;27:440-6.

2. Delforge M, Ludwig H. How I manage the toxicities of myeloma drugs. Blood. 2017;129:2359-67.

3. Smith RE. Trends in recommendations for myelosuppressive chemotherapy for the treatment of solid tumors. J Natl Compr Canc Netw. 2006;4: 649-58.

4. Kuter DJ. Managing thrombocytopenia associated with cancer chemotherapy. Oncology. 2015;29: 282-94.

5. Taylor SJ, Duyvestyn JM, Dagger SA, et al. Preventing chemotherapy-induced myelosuppression by repurposing the FLT3 inhibitor quizartinib. Sci Transl Med. 2017;9(402):eaam8060.

6. Bryer E, Henry D. Chemotherapy-induced anemia: etiology, pathophysiology, and implications for contemporary practice. Int J Clin Transf Med. 2018;6:21-31.

7. Aapro M, Beguin Y, Bokemeyer C, et al. Management of anaemia and iron deficiency in patients with cancer: ESMO Clinical Practice Guidelines. Ann Oncol. 2018;29:iv96-iv110. 
8. Klastersky J, de Naurois J, Rolston K, et al. Management of febrile neutropaenia: ESMO Clinical Practice Guidelines. Ann Oncol. 2016;27: v111-v118.

9. Crawford J, Denduluri N, Patt D, et al. Relative dose intensity of first-line chemotherapy and overall survival in patients with advanced non-small-cell lung cancer. Support Care Cancer. 2020;28:925-32.

10. Lyman GH. Chemotherapy dose intensity and quality cancer care. Oncology. 2006;20:16-25.

11. Havrilesky LJ, Reiner M, Morrow PK, Watson H, Crawford J. A review of relative dose intensity and survival in patients with metastatic solid tumors. Crit Rev Oncol Hematol. 2015;93:203-10.

12. Benson $\mathrm{AB}$, Venook $\mathrm{AP}, \mathrm{Al}$-Hawary $\mathrm{MM}$, et al. NCCN guidelines insights: colon cancer, version 2. 2018. J Natl Compr Canc Netw. 2018;16:359-69.

13. Elegbede AA, Gibson AJ, Fu H, et al. Real-world adherence to guideline-recommended treatment for small cell lung cancer. Am J Clin Oncol. 2020;43:236-42.

14. Feinberg B, Kish J, Dokubo I, Wojtynek J, Gajra A, Lord K. Comparative effectiveness of palliative chemotherapy in metastatic breast cancer: a realworld evidence analysis. Oncologist. 2020;25: 319-26.

15. Kalemkerian GP, Loo BW, Akerley W, et al. NCCN guidelines insights: small cell lung cancer, version 2.2018. J Natl Compr Canc Netw. 2018;16:1171-82.

16. Gradishar WJ, Anderson BO, Abraham J, et al. Breast cancer, version 3.2020, NCCN clinical practice guidelines in oncology. J Natl Compr Canc Netw. 2020;18:452-78.

17. Povsic M, Enstone A, Wyn R, Kornalska K, Penrod JR, Yuan Y. Real-world effectiveness and tolerability of small-cell lung cancer (SCLC) treatments: a systematic literature review (SLR). PLoS One. 2019;14: e0219622.

18. Gascón P, Rodríguez CA, Valentín V, et al. Usefulness of the perform questionnaire to measure fatigue in cancer patients with anemia: a prospective, observational study. Support Care Cancer. 2013;21: 3039-49.

19. Fortner BV, Tauer KW, Okon T, Houts AC, Schwartzberg LS. Experiencing neutropenia: quality of life interviews with adult cancer patients. BMC Nurs. 2005;4:4.

20. Williams LA, Bohac C, Hunter S, Cella D. Patient and health care provider perceptions of cancer- related fatigue and pain. Support Care Cancer. 2016;24:4357-63.

21. Sasaki H, Tamura K, Naito Y, et al. Patient perceptions of symptoms and concerns during cancer chemotherapy: 'affects my family' is the most important. Int J Clin Oncol. 2017;22:793-800.

22. Carelle N, Piotto E, Bellanger A, Germanaud J, Thuillier A, Khayat D. Changing patient perceptions of the side effects of cancer chemotherapy. Cancer. 2002;95:155-63.

23. Mitchell T. The social and emotional toll of chemotherapy-patients' perspectives. Eur J Cancer Care. 2007;16:39-47.

24. Fortner B, Tauer K, Zhu L, Ma L, Schwartzberg L. The impact of medical visits for chemotherapy-induced anemia and neutropenia on the patient and caregiver: a national survey. Community Oncol. 2004;1:211-7.

25. Corey-Lisle PK, Desrosiers MP, Collins $\mathrm{H}$, et al. Transfusions and patient burden in chemotherapyinduced anaemia in France. Ther Adv Med Oncol. 2014;6:146-53.

26. Shreay S, Desrosiers M-P, Corey-Lisle P, Payne K. A retrospective study to evaluate the time burden associated with outpatient red blood transfusions indicated for anemia due to concomitantly administered chemotherapy in cancer patients. Support Care Cancer. 2013;21:1335-400.

27. Epstein R, Krenitsky J, Weerasinghe RK, Parrish AS, Sanborn RE, Salimi T. Real-world burden of myelosuppression in patients with small cell lung cancer (SCLC): retrospective, longitudinal data analysis. J Clin Oncol. 2020;38(15_suppl):e19300

28. Weycker D, Silvia A, Richert-Boe K, et al. Use and patterns of supportive care among patients receiving myelosuppressive chemotherapy for breast cancer, colorectal cancer, lung cancer, or nonHodgkin's lymphoma in US clinical practice. Blood. 2016;128:5909.

29. Culakova E, Thota R, Poniewierski MS, et al. Patterns of chemotherapy-associated toxicity and supportive care in US oncology practice: a nationwide prospective cohort study. Cancer Med. 2014;3: 434-44.

30. Tang WY, Vlahiotis A, Fung S, Arantes L, Chambers R. Current burden of chemotherapy induced anemia and patterns of erythropoiesis-stimulating agents utilization. J Clin Oncol. 2018;36:e18765.

31. Nordstrom BL, Luo W, Fraeman K, Whyte JL, Nordyke RJ. Use of erythropoiesis-stimulating agents among chemotherapy patients with hemoglobin 
exceeding 12 grams per deciliter. J Manag Care Pharm. 2008;14:858-69.

32. Granfortuna J, Shoffner K, DePasquale SE, Badre S, Bohac C, De Oliveira BC. Transfusion practice patterns in patients with anemia receiving myelosuppressive chemotherapy for nonmyeloid cancer: results from a prospective observational study. Support Care Cancer. 2018;26:2031-8.

33. Estcourt LJ, Birchall J, Allard S, et al. Guidelines for the use of platelet transfusions. Br J Haematol. 2017;176:365-94.

34. Denduluri N, Lyman GH, Wang Y, et al. Chemotherapy dose intensity and overall survival among patients with advanced breast or ovarian cancer. Clin Breast Cancer. 2018;18:380-6.

35. Maiti R. Metronomic chemotherapy. J Pharmacol Pharmacother. 2014;5:186-92.

36. Roe H, Lennan E. Role of nurses in the assessment and management of chemotherapy-related side effects in cancer patients. Nurs Res Rev. 2014;4: 103-15.

37. Prip A, Møller KA, Nielsen DL, Jarden M, Olsen MH, Danielsen AK. The patient-healthcare professional relationship and communication in the oncology outpatient setting: a systematic review. Cancer Nurs. 2018;41:E11-e22.

38. Hershman D, Calhoun E, Zapert K, Wade S, Malin J, Barron R. Patients' perceptions of physician-patient discussions and adverse events with cancer therapy. Arch Drug Inf. 2008;1:70-8.

39. Oncology L. Covid-19: Global consequences for oncology. Lancet Oncol. 2020;21:467.

40. Casanova M, Pagani Bagliacca E, Silva M, et al. How young patients with cancer perceive the COVID-19 (coronavirus) epidemic in Milan, Italy: is there room for other fears? Pediatr Blood Cancer. 2020;67:e28318. 